\title{
CRITERIOS JURISDICCIONALES PARA LA RESOLUCIÓN DE LOS CONFLICTOS ENTRE LAS LIBERTADES DE EXPRESIÓN Y DE INFORMACIÓN Y EL DERECHO AL HONOR, A LA INTIMIDAD Y A LA PROPIA IMAGEN
}

\author{
Manuel Carrasco Durán \\ Doctor en Derecho \\ Profesor de Derecho Constitucional \\ Universidad de Sevilla (España)
}

La libertad de expresión y de información y el derecho al honor, a la intimidad y a la propia imagen constituyen una fuente permanente de problemas debido a la frecuencia con que entran en conflicto los intereses que ambos derechos pretenden salvaguardar, esto es, y sin perjuicio de que posteriormente efectuemos alguna precisión, por un lado, el interés de los ciudadanos, fundamentalmente los periodistas, aunque no sólo ellos, por manifestar en público sus puntos de vista sobre temas de actualidad o por llevar al conocimiento de los demás ciudadanos acontecimientos o conductas de relevancia pública y el interés de los potenciales receptores de dichas opiniones e informaciones por alcanzar el conocimiento o formarse un juicio sobre hechos sociales, y, por otro lado, el interés de las personas implicadas en los hechos o acontecimientos sobre los que versan aquellas opiniones e informaciones en preservar su estima -ya sea su autoestima, ya sea el buen concepto que deban merecer del común de los ciudadanos-, o en mantener la reserva de hechos o datos relativos a su vida privada o familiar, el control de la utilización pública de su imagen, o, simplemente, su anonimato.

El problema anterior se agudiza si se tiene en cuenta la concisión de los preceptos constitucionales que reconocen los derechos señalados, los cuales aportan pocos elementos para la resolución de dichos conflictos, el carácter poco preciso de nociones tales como honor e intimidad, para cuya definición siempre hay que acudir a precomprensiones sociales sobre lo que signifiquen tales conceptos, lo que les confiere la volatilidad inherente a los siempre cambiantes juicios de origen social, y la variedad inagotable de nuevos supuestos de conflicto a causa del interés económico que las personas famosas pueden tener en la explotación controlada de su imagen o en la difusión de determinados hechos o actos de su intimidad (por ejemplo, mediante exclusivas con algún medio de comunicación) y de la rentabilidad que obtienen los medios de comunicación con la divulgación de acontecimientos o datos relativos a personas que concitan el interés y la curiosidad del público, con independencia del valor informativo, en ocasiones muy escaso, de los datos que motivan la noticia.

Los factores que se acaban de citar determinan que la jurisprudencia, en esta materia, tenga que limitar sus pronunciamientos, en el plano teórico, a especificar principios muy generales sobre el contenido y la interpretación de los derechos en con- 
flicto. Paralelamente, la variedad que presentan los distintos supuestos de colisión entre tales derechos hace que adquiera importancia particular en las resoluciones judiciales la ponderación de las circunstancias propias de cada caso controvertido. Sea como sea, el hecho es que la mencionada concisión de los preceptos constitucionales y la propia variedad de supuestos posibles proporcionan a la jurisprudencia una importancia particular, especialmente, a la hora de determinar el valor que deba darse a cada uno de los elementos y circunstancias concurrentes en dichas situaciones de conflicto, con vistas a establecer cuáles de los elementos e intereses en juego prevalecen en cada caso.

Seguidamente se expone un resumen de la jurisprudencia del Tribunal Constitucional español sobre los supuestos de conflicto entre los derechos citados. Ciertamente, cada sociedad y cada ordenamiento se mueven en coordenadas propias que no siempre hacen idóneo el recurso al derecho comparado, pero la homogeneidad de las conclusiones a las que suele abocar la hermenéutica de los artículos de la Constitución que reconocen los derechos de los ciudadanos en los Estados democráticos, que, más allá de su respectiva singularidad, comparten un presupuesto común favorable a la aplicación de los derechos constitucionales como fundamento del orden político y de la paz social, y la semejanza de los supuestos prácticos de conflicto entre tales derechos que pueden darse en distintas sociedades, pueden incrementar la utilidad de las reflexiones que se desarrollan a continuación.

\section{Los preceptos constitucionales, conceptos y notas generales}

Comenzamos examinando brevemente los términos del reconocimiento constitucional de los derechos indicados, la definición que el Tribunal Constitucional ha realizado de cada uno de ellos y otras notas generales que complementan dichas definiciones.

\subsection{El derecho al honor, a la intimidad y a la propia imagen}

El artículo 18.1 de la Constitución expresa, escuetamente, que «se garantiza el derecho al honor, a la intimidad personal y a la propia imagen". Se trata por lo tanto de tres derechos distintos que han sido definidos separadamente por el Tribunal Constitucional.

En relación con el derecho al honor, establece la STC $223 / 1992^{1}$ que su definición «hay que buscarla en el lenguaje de todos, en el cual suele el pueblo hablar a su vecino, y el Diccionario de la Real Academia nos lleva del honor a la buena reputación (concepto utilizado por el Convenio de Roma ${ }^{2}$ ), la cual-como la fama y aun la honra-

${ }^{1}$ Con la abreviatura STC nos referimos a las sentencias del Tribunal Constitucional.

Las sentencias del Tribunal Constitucional que examinamos se han producido en recursos de amparo. En España, el recurso de amparo es un proceso extraordinario mediante el que el individuo que se considera perjudicado por una vulneración de algún derecho de los incluidos en los artículos 14 a 29 y 30.2 de la Constitución puede acudir al Tribunal Constitucional en demanda del restablecimiento del derecho que haya motivado la controversia. Es condición para la admisión del recurso de amparo haber agotado, previamente, los recursos establecidos en el ordenamiento ante los órganos judiciales ordinarios para el conocimiento del mismo asunto que se pretende someter a la consideración del Tribunal Constitucional.

Se refiere al Convenio Europeo para la Protección de los Derechos Humanos y de las Libertades Fundamentales, de 4 de novi- 
consiste en la opinión que las gentes tienen de una persona (...). El denominador común de todos los ataques o intromisiones ilegítimas en el ámbito de protección de este derecho es el desmerecimiento en la consideración ajena como consecuencia de expresiones proferidas en descrédito o menos precio de alguien o que fueren tenidas en el concepto público por afrentosas. Todo ellos nos sitúa en el terreno de los demás, que no son sino la gente, cuya opinión colectiva marca en cualquier lugar y tiempo el nivel de tolerancia o de rechazo."

Marc Carrillo ordena los conceptos manejados en el pronunciamiento anterior y señala que el derecho al honor tiene una doble vertiente: «desde una perspectiva subjetiva es "el sentimiento de estimación que una persona tiene de sí misma en relación con la conciencia de la propia dignidad moral". Mientras que desde una vertiente objetiva se trataría de "la reputación, buen nombre o fama de que goza ante los demás" "3. Por su parte, el artículo $7^{\circ} .7$ de la Ley Orgánica 1/1982, de Protección Civil del Derecho al Honor, a la Intimidad y a la Propia Imagen (en adelante, LODH), en su redacción actual $^{4}$, conceptúa los ataques al derecho al honor como «la imputación de hechos o la manifestación de juicios de valor a través de acciones o expresiones que de cualquier modo lesionen la dignidad de otra persona, menoscabando su fama o atentando contra su propia estimación."

De este modo, para determinar si los términos de una opinión o una información vulneran el derecho al honor, hay que situarse en el terreno de las creencias y los prejuicios sociales, que marcan las circunstancias, los juicios de valor y las expresiones que, aplicadas a una persona, pueden hacerla desmerecer en el concepto social o en su buen nombre dentro de la comunidad. La propia LODH, en su artículo $2^{\circ} \cdot 1$, señala que "la protección civil del honor, de la intimidad y de la propia imagen quedará delimitada por las leyes y por los usos sociales atendiendo al ámbito que, por sus propios actos, mantenga cada persona reservado para sí misma o su familia». Dejando aparte, de momento, la consideración de la conducta de la propia persona, resulta esclarecedora la llamada que la Ley hace a los usos sociales como dato para la interpretación de los supuestos que, al conllevar la vulneración de alguno de los derechos indicados, permiten que entren en juego los mecanismos de protección de tales derechos.

Del mismo modo, las circunstancias concretas en que se producen los hechos sobre los que se opina o se informa.

Dos notas adicionales para terminar con el derecho al honor. En primer lugar, la importancia que tiene el contexto en el que se emiten las expresiones que pueden motivar una controversia sobre tal derecho, de modo que ha considerado el Tribunal Supremo, en su sentencia de 30 de abril de 1990, que "cualquier palabra puede ser o no injuriosa cuando se contrasta dentro del contexto en que se enmarca". Esto es que, además de la consideración social, hay que tener en cuenta las circunstancias de los hechos. Como bien sintetiza la STC 185/1989, el derecho al honor "es un derecho respecto al cual las circunstancias concretas en que se producen los hechos y las ideas

embre de 1950.

${ }^{3}$ CARRILLO, M.; Los límites a la libertad de prensa en la Constitución española de 1978, Promociones y Publicaciones Universitarias (PPU), 1987, p. 50.

Producto de la modificación efectuada por la Ley Orgánica 10/1995, de 23 de noviembre, del Código Penal. 
dominantes que la sociedad tiene sobre la valoración de aquél son especialmente significativas para determinar si se ha producido o no lesión".

Finalmente, el derecho al honor incluye la protección del prestigio profesional de las personas o la consideración social que merecen en el desarrollo de su trabajo, ya que «la opinión que la gente pueda tener de cómo trabaja cada cual, resulta fundamental para el aprecio social y tiene una influencia decisiva en el bienestar propio de la familia, pues de él dependen no ya el empleo o el paro, sino el estancamiento o el ascenso social, con las consecuencias económicas que le son inherentes" (STC 223/1992). En concreto, se considera que cla difusión de hechos directamente relativos al desarrollo y ejercicio de la actividad profesional puedan ser constitutivos de una intromisión ilegítima en el derecho al honor cuando excedan de la libre crítica a la labor profesional, siempre que por su naturaleza, características y forma en que se hace la divulgación la hagan desmerecer en la consideración ajena de su dignidad como persona" (STC 40/1992). No toda crítica, por lo tanto, supone una vulneración del derecho al honor, sino sólo las que tengan como efecto el descrédito en la consideración ajena de la persona.

El derecho a la intimidad queda configurado por la STC 57/1994 como «la existencia de un ámbito propio y reservado frente a la acción y el conocimiento de los demás, necesario -según las pautas de nuestra cultura- para mantener una calidad mínima de vida humana." Por lo tanto, se refiere al derecho a mantener preservados del conocimiento público hechos y comportamientos cuyo especial carácter privado los hace merecedores de dicha reserva. Mientras el honor se refiere a un bien de la persona, por así decirlo, puramente espiritual, como es la estima, la intimidad alude más bien a un ámbito reservado que engloba elementos de carácter objetivo, como son determinados datos y comportamientos de naturaleza privada.

Las intromisiones en la intimidad alcanzan también al ámbito familiar. Así, la STC 231/1988 señala que "el derecho la intimidad personal y familiar se extiende no sólo a aspectos de la vida propia y personal, sino también a determinados aspectos de la vida de otras personas con las que se guarde una especial y estrecha vinculación, como es la familiar, aspectos que, por la relación o vínculo existente con ellas, inciden en la propia esfera de la personalidad del individuo que los derechos del artículo 18.1 protegen." Supuestos especiales son los de intromisiones en la intimidad de personas fallecidas, en los que, como dice Lluís de Carreras, aunque una vez muerta una persona, su personalidad $-y$, por tanto, el derecho a la intimidad- se extingue, los vínculos afectivos con el fallecido trasladan a los familiares la acción de protección del derecho a la intimidad ${ }^{5}$, en atención al "dolor y la angustia de los familiares cercanos al fallecido» (STC 231/1988), y los de lesiones en el derecho a la intimidad de los menores. En definitiva, como expresa también la STC 231/1988, "ciertos eventos que puedan ocurrir a padres, cónyuges o hijos tienen normalmente, y dentro de las pautas culturales de nuestra sociedad, tal trascendencia para el individuo, que su indebida publicidad o difusión incide directamente en la propia esfera de su personalidad. Por lo que existe al respecto un derecho -propio, y no ajeno- a la intimidad, constitucionalmente protegido." Se entiende, así pues, que los familiares próximos de los fallecidos o de los meno-

${ }^{5}$ DE CARRERAS SERRA, L.; El régimen jurídico de la información (periodistas y medios de comunicación), Ariel, Barcelona, 1996, p. 80. 
res que sufran ataques en su derecho a la intimidad tienen un derecho propio a reaccionar contra dichas conductas ya que éstas, indirectamente, dañan también la intimidad de dichos familiares, en razón de la comunidad afectiva que surge de la relación establecida en el seno de una familia.

Aunque el reconocimiento del derecho a la intimidad viene de la mano de algunas libertades tradicionales, como la inviolabilidad del domicilio y de la correspondencia, «el avance de la tecnología actual y el desarrollo de los medios de comunicación de masas ha obligado a extender esa protección más allá del domicilio como espacio físico en que normalmente se desenvuelve la intimidad y del respeto a la correspondencia... De aquí el reconocimiento global de un derecho a la intimidad o a la vida privada que abarque las intromisiones que por cualquier medio puedan realizarse en ese ámbito reservado de la vida" (STC 110/1984). Se trata, por lo tanto, de mantener la reserva sobre comportamientos y actuaciones privadas de la persona, sea cual sea el lugar en el que aquéllos se realicen.

Finalmente, el derecho a la propia imagen puede definirse como el derecho a ser uno mismo y el derecho a que no se haga uso de la imagen de uno sin su consentimiento ${ }^{6}$. Sólo examinaremos supuestos relativos a este derecho en casos que presentan una cierta conexión con el derecho a la intimidad, en relación con actividades propias de la profesión periodística.

\subsection{Las libertades de expresión y de información}

El artículo 20.1 de la Constitución reconoce y protege, en su apartado a), el derecho «a expresar y difundir libremente los pensamientos, ideas y opiniones mediante la palabra, el escrito o cualquier otro medio de reproducción”, y en su apartado d), el derecho "a comunicar o recibir libremente información veraz por cualquier medio de difusión." Son, pues, dos derechos distintos, ya que, como dice la STC 107/1988, «nuestra Constitución consagra por separado la libertad de expresión -art. 20.1.a)- y la libertad de información -art. 20.1.d)- acogiendo una concepción dual, que se aparte de la tesis unificadora, defendida por ciertos sectores doctrinales y acogida en los artículos 19.2 del Pacto Internacional de Derechos Civiles y Políticos de Nueva York y 10.1 del Convenio para la Protección de los Derechos Humanos y de las Libertades Fundamentales de Roma.»

Como continúa diciendo la misma sentencia, "según esa configuración dual -que normativiza a nivel constitucional la progresiva autonomía que ha ido adquiriendo la libertad de información respecto de la libertad de expresión en la que tiene su origen y con la cual sigue manteniendo íntima conexión y conserva elementos comunes-, la libertad del artículo 20.1.a) tiene por objeto la expresión de pensamientos, ideas y opiniones, concepto amplio dentro del cual deben también incluirse las creencias y juicios de valor; y el de la libertad del artículo 20.1.d) el comunicar y recibir libremente información sobre hechos, o tal vez más restringidamente, sobre hechos que puedan considerarse noticiables. »

${ }^{6}$ PÉREZ ROYO, J.; Curso de Derecho Constitucional, Marcial Pons, Madrid, $4^{2}$ ed., 1997 (1² ed., 1994), p. 295. 
La segunda de las libertades anteriores, esto es, la libertad de información, se refiere, pues, al derecho a dar al conocimiento público hechos ocurridos en el mundo de la realidad, mientras que la libertad de expresión ampara el derecho a manifestar los pensamientos, ideas, opiniones y valoraciones que merecen a cada cual tales hechos. Cuando informaciones y opiniones van mezcladas en una misma noticia, el Tribunal Constitucional calificará el derecho ejercido según uel elemento preponderante de lo comunicado" (STC 172/1990).

\section{Supuestos de conflicto entre el derecho al honor, a la intimidad y a la propia imagen y las libertades de expresión y de información}

Ya la propia Constitución es consciente de los supuestos problemáticos que la colisión de los intereses contrapuestos que encarnan los derechos anteriores puede ocasionar. Así, su artículo 20.4, refiriéndose a las libertades de expresión y de información, expresa que cestas libertades tienen su límite en el respeto a los derechos reconocidos en este Título, en los preceptos de las leyes que lo desarrollan y, especialmente, en el derecho al honor, a la intimidad, a la propia imagen y a la protección de la juventud y de la infancia."

El Tribunal Constitucional, por su parte, ha pasado por tres etapas a la hora de enjuiciar los supuestos de colisión en el ejercicio de los derechos y libertades anteriores. Así, desde el comienzo de su actividad, en 1980, consideró que el derecho al honor tenía prevalencia en todo caso frente a las libertades de expresión e información, tomando como base para esta interpretación el reconocimiento expreso de aquél como límite de dichas libertades que hace el artículo 20.4 de la Constitución. Sin embargo, a partir de la STC 104/1986, sus pronunciamientos viraron al extremo opuesto y, como consecuencia de la importación de jurisprudencia del Tribunal Europeo de Derechos Humanos ${ }^{7}$, comenzó a conferir a las libertades del artículo 20 una posición hegemónica, hasta el punto de privar de protección al derecho al honor en los casos de conflicto con éste del ejercicio de aquellas libertades, al considerar el papel preponderante que, a diferencia del honor o de la intimidad, que quedan en un plano estrictamente privado, juega la libertad de expresión en un sistema democrático, en el que contribuye a la formación de una opinión pública libre y plural.

Las dos tendencias anteriores se revelan inadecuadas, ya que la Constitución sólo puede ser interpretada considerando que todos sus preceptos tienen valor y deben ser aplicados en la realidad. La oposición de los intereses amparados por derechos distintos debe motivar un esfuerzo para hacer compatibles, siempre que ello sea posible, la

${ }^{7}$ El Convenio Europeo de para la Protección de los Derechos Humanos y de las Libertades Fundamentales establece en sus Títulos III y IV la posibilidad de que, cumpliendo determinados requisitos procesales (particularmente, deben agotarse todos los procesos y recursos ante órganos jurisdiccionales que sean áptos, según la legislación nacional, para el conocimiento y resolución del asunto controvertido), «cualquier persona física, organización no gubernamental o grupo de particulares, que se considere víctima de una violación" de los derechos reconocidos en el Convenio por alguno de los Estados firmantes acuda a la Comisión Europea de Derechos Humanos en demanda de protección de tales derechos (art. 25 del Convenio). Si la Comisión admite la demanda, tras comprobar que cumple los requisitos establecidos en el Convenio para la utilización de este recurso y que no es incompatible con las disposiciones del Convenio, y el demandante y el Estado demandado no alcanzan un arreglo amistoso, el caso se pasa al Tribunal Europeo de Derechos Humanos, que se pronuncia mediante una resolución jurisdiccional que toma forma de sentencia. Esta última circunstancia sólo es posible si el Estado demandado ha manifestado previamente, de forma expresa, su sometimiento a la jurisdicción del Tribunal Europeo de Derechos Humanos (art. 48 del Convenio). 
realización del máximo posible de tales intereses en las situaciones en que aquéllos puedan llevarse a la realidad sin negarse mutuamente. En aquellos casos en que la realización simultánea de tales intereses sea imposible, por incompatibilidad de los mismos, la solución debe venir de la ponderación de las circunstancias propias de cada caso, con vistas a determinar, según las características especiales de cada situación, a cuál de los derechos se le da preponderancia. Y ello, sin otorgar prevalencia absoluta, a priori y en toda circunstancia, a uno u otro derecho, lo cual sería tanto como reconocer que un derecho vale más que el otro, contraviniendo la voluntad de la Constitución que sitúa ambos en el mismo plano, en cuanto a su valor y a sus técnicas de protección.

Finalmente, a partir de la STC 105/1990, el Tribunal Constitucional ha adoptado una línea ecléctica, que da importancia capital al examen de las circunstancias propias de cada supuesto, y que se mantiene en la actualidad ${ }^{8}$. Los elementos clave para comprender esta tendencia son los siguientes:

\subsection{Como principio de partida, el valor preponderante de las libertades de ex- presión y de opinión}

Como dice la STC 51/1989, y reiteran múltiples pronunciamientos del Tribunal Constitucional, «las libertades del artículo 20 de la Constitución no sólo son derechos fundamentales de cada persona, sino que también significan el reconocimiento y garantía de la opinión pública libre, elemento indispensable del pluralismo político en un Estado democrático, que por lo mismo trasciende el significado común y propio de los demás derechos fundamentales."

Las libertades citadas, por lo tanto, además de su condición de derechos individuales, tienen un significado institucional, ya que son requisito para la formación y el desenvolvimiento de una opinión pública libre, que constituye elemento indispensable para la participación de la sociedad en un Estado democrático, para el control social del ejercicio del poder y para la correcta determinación de la voluntad social en las elecciones que concretarán los integrantes del Parlamento, como órgano de poder directamente representativos de la sociedad. Ello hace que dichas libertades tengan, como principio general, un valor preponderante sobre el derecho al honor y sus complementarios cuando entran en disputa.

Sin embargo, la Constitución sólo ampara un ejercicio correcto de las libertades de expresión y de información, o sea, un ejercicio de tales libertades que cumpla con determinados requisitos. Esto quiere decir que, en posibles situaciones de conflicto entre estas libertades y el derecho al honor, el Tribunal habrá de preguntarse, primero, si realmente las opiniones o las informaciones comunicadas han afectado a los bienes protegidos por los derechos del artículo 18 de la Constitución (la estima propia o el concepto o buen nombre social de la persona, en el caso del derecho al honor, el ámbito reservado de vida privada de la persona y de su familia, en el caso del derecho a la intimidad, y el interés en disponer de la utilización de la imagen, cuando estamos ante el derecho a la propia imagen). Lógicamente, sólo existe la posibilidad de que se haya ${ }^{8}$ Sobre la evolución de la jurisprudencia del Tribunal Constitucional en el tema, GIMENO SENDRA, V., y GARBERI LLOBRE-
GAT, J.; Los procesos de amparo (ordinario, constitucional e internacional), Colex, Madrid, 1994, pp. 50 y s. 
vulnerado alguno de tales derechos si tales bienes jurídicos resultan afectados por las opiniones o las informaciones.

Si se considera que tales bienes jurídicos han resultado afectados, el Tribunal, entonces, tendrá que volver su mirada a la forma como se ha ejercido la libertad de opinión o la libertad de información en la situación específica objeto de controversia. En tales casos, si se comprueba que la noticia o el juicio de valor comunicados al público cumplen con los requisitos fijados en la Constitución y en la jurisprudencia para entender que estamos ante un ejercicio lícito de las libertades de expresión y de información, los datos publicados quedarán amparados por dichas libertades constitucionales. Por el contrario, si del examen de lo publicado se deriva que no se ha cumplido alguno de dichos requisitos, se habrá producido una vulneración del derecho que haya entrado en conflicto en la situación concreta, ya sea el derecho al honor, ya el derecho a la intimidad, ya el derecho a la propia imagen".

\subsection{Requisitos para el correcto ejercicio de las libertades de expresión y de información y supuestos de vulneración del derecho al honor, a la intimidad y a la propia imagen}

\subsubsection{En relación con la libertad de expresión}

Manifiesta la STC 107/1988 que «aparecerán desprovistas de valor de causa de justificación las frases formalmente injuriosas o aquéllas que carezcan de interés público y, por tanto, resulten innecesarias a la esencia del pensamiento, idea y opinión que se expresa... La eficacia justificadora de dichas libertades pierde razón de ser en el supuesto de que se ejerciten en relación con conductas privadas carentes de interés público y cuya difusión y enjuiciamiento públicos son innecesarios, por tanto, para la formación de la opinión pública libre en atención a la cual se reconoce su posición prevalente".

Por lo tanto, son dos los límites al ejercicio de la libertad de expresión:

a) La libertad de expresión no ampara el insulto (STC 85/1992). Naturalmente, en ocasiones, para determinar la carga injuriosa de algunas expresiones habrá que acudir al concepto social o al contexto en el que tales opiniones se hayan vertido.

Las opiniones se pueden publicar de muy distinta forma, y habrá que escoger, pues, expresiones que no resulten insultantes.

\footnotetext{
9

Hay que diferenciar lo que es afectar a un derecho fundamental y vulnerar el mismo derecho. Un derecho queda afectado cuando una actuación percute $o$ incide en los bienes jurídicos o los intereses protegidos por tal derecho, en nuestro caso, resumidamente, la estima, la intimidad, el interés en disponer de la propia imagen. Se produce la vulneración cuando la "afectación" de aquel derecho no puede ampararse en un derecho o bien reconocido en la Constitución con valor prevalente al que resulta afectado, como es el supuesto del ejercicio correcto de las libertades de expresión e información. Por el contrario, en los supuestos de ejercicio de tales libertades cumpliendo con los condicionantes derivados por la jurisprudencia de la interpretación de los preceptos constitucionales, el derecho al honor o sus complementarios habrán quedado, todo lo más, afectados, pero no se habrá producido vulneración de ellos, por lo que, en estas circunstancias, estaremos ante un ejercicio correcto y legitimo de las libertades ínsitas al derecho constitucional a la comunicación pública. Cumpliendo los requisitos señalados, la Constitución ampara la percusión o incidencia que se haya producido en los bienes o intereses protegidos por el derecho al honor, a la intimidad y a la propia imagen.
} 
No obstante, uel carácter molesto o hiriente de una información no constituye en sí un límite al derecho a la información misma (Tribunal Europeo de Derechos Humanos, caso Lingens, sentencia de 8 de julio de 1986, núm. 41); para sobrepasar el límite de lo tolerable, esas expresiones deben poder ser consideradas como expresiones insultantes, insinuaciones insidiosas y vejaciones innecesarias que sólo puedan entenderse como insultos o descalificaciones dictadas no por un ánimo o por una función informativa, sino, como ha dicho la STC 105/1990, con malicia calificada por un ánimo vejatorio o la enemistad pura y simple" (STC 171/1990).

Señala también la STC 50/1983 que «ni la Constitución ni la Ley pueden garantizar al individuo contra el deshonor que nazca de sus propios actos." Quiere decirse que se puede informar objetivamente de actos de personas tenidos en el concepto público por deshonrosos, pero que han sucedido en la realidad.

b) Tampoco quedan protegidas por la libertad de expresión las frases que carezcan de interés público y las que resulten extrañas al hilo conductor de la opinión que se expresa.

Los pensamientos, ideas $\mathrm{u}$ opiniones enjuician siempre datos de la realidad $\mathrm{o}$, al menos, parten de ellos para construir las conjeturas que se publican. Precisamente, para que los pensamientos, ideas u opiniones constituyan supuestos de ejercicio lícito de la libertad de expresión es necesario que la realidad que se toma como base esté formada por hechos que conciten un valor informativo, esto es, que pueda apreciarse un interés público en su difusión. Las ideas o juicios de valor sobre realidades privadas, sin interés público, no justifican su difusión.

Tampoco ampara la libertad de expresión tomar como pretexto un hecho de interés público para manifestar opiniones extrañas al propósito informativo principal. Viene a decir el Tribunal Constitucional que, si se está informando u opinando sobre una determinada cuestión de actualidad, las opiniones deben ceñirse a esa cuestión o a aspectos complementarios de ella, pero no puede aprovecharse la ocasión para opinar sobre datos sin interés público ajenos a los que motivan las opiniones principales.

Ejemplo típico es el caso resuelto en la STC 105/1990, sobre un periodista deportivo que, en una emisión radiofónica, dentro de una serie de opiniones muy críticas al entonces Presidente de la Federación Española de Fútbol, además de apoyar su acusación de que dicho Presidente se estaba llevando dinero de la Federación con epítetos de inequívoco contenido injurioso, sugirió que, después de una reunión en los locales de la Federación, aquél se había marchado a la suite de un hotel donde lo esperaban varias señoritas y que aquella noche corrió el champán. El Tribunal Constitucional ha admitido, incluso, que en un contexto de conflicto entre las personas que integran el aparato administrativo de un órgano público y los afectados por las actuaciones de dicho órgano, pueda darse publicidad a la hipótesis de que alguien pudiera estar llevándose dinero de dicho órgano (siempre que tal sospecha se base en opiniones que tengan una cierta reiteración que les dé credibilidad y que la fuente de información sea fiable). Lo que no se admite es, con el pretexto de dar esa información, insultar al personaje sobre el que dicha información versa, ni dar publicidad a conductas íntimas que, incluso aunque hubieran sido ciertas, quedarían fuera del objeto propio de la información que se quiere comunicar. 
En la misma línea de la anterior, no se concede el amparo a los autores de una información relativa a un accidente de aviación en el que murió la tripulación y el pasaje, ya que, junto al relato de la información, propiamente dicha, se vertían expresiones injuriosas o vejatorias hacia el piloto, al que se tildaba de "cachondo mental" (esta expresión se utiliza coloquialmente en España para designar a quien es incapaz de tomarse nada mínimamente en serio) y de "mal educado y grosero" (STC 172/1991, caso accidente de avión-2).

Dentro de las coordenadas citadas, juega gran importancia el contexto en el que acontecen los hechos sobre los que se opina, ya que las circunstancias de interés público que rodeen determinados acontecimientos pueden explicar la relevancia pública de las opiniones vertidas a propósito de dichas circunstancias, siempre que no entrañen efecto injurioso o vejatorio para el afectado. Así, resulta interesante la STC 171/1991 (caso accidente de avión-1), relativa a otra información sobre los mismos hechos de la sentencia 172/1991 (accidente de avión-2) aparecida en otro periódico, en la que, a diferencia de la segunda sentencia citada, el Tribunal Constitucional concedió el amparo a los representantes del medio de comunicación. Puede verse, por comparación, qué circunstancias cita el Tribunal Constitucional como justificativas de la información en la STC 171/1991, a diferencia de los motivos que lo llevaron a desestimar el recurso de amparo en la STC 172/1991. En este sentido, señala la STC 171/1991 que "teniendo en cuenta las circunstancias del caso, el contenido mismo de las expresiones cuestionadas y el que las mismas tenían como fondo un análisis crítico de un accidente aéreo en el marco de una excesiva siniestralidad del transporte aéreo en aquel momento, no cabe considerar que las expresiones utilizadas fueran innecesarias y gratuitas en relación con la información, ni que por su contenido y forma tuvieran una finalidad vejatoria o fueran producto de una enemistad personal. No eran así irrelevantes las informaciones publicadas sobre las cualidades personales del piloto, ponderándose, como se precisa en la demanda, tanto las innegables cualidades positivas, tratarse de un piloto muy capacitado, experimentado y de los más expertos, su carácter jovial y extrovertido, como también sus defectos, en sí mismos, además, no contrarios a la honra o a la buena fama, como el carácter irascible, o el que estuviese pasando una mala racha personal y hubiese sufrido depresiones. Ello se expone, además, para cuestionar la diligencia de la dirección de la compañía al permitirle volar en esa situación. Se trataba de datos y calificaciones relevantes para la información y, además, presentadas dentro de los límites de lo tolerable, al no utilizarse expresiones vejatorias ni suponer un propósito de descalificación o descrédito global de la persona. El órgano judicial debe examinar las expresiones utilizadas dentro del contexto general de la información en que se realizan, y en ese contexto, teniendo en cuenta el interés público de la información efectuada, tales expresiones no pueden considerarse como afirmaciones absolutamente innecesarias ni que utilicen términos reprobables y vejatorios para el afectado, "

\subsubsection{En relación con la libertad de información}

La Constitución sólo ampara el derecho a comunicar o recibir libremente información veraz. Este requisito, la veracidad, es la principal fuente de límites a la libertad de información y, por lo mismo, la principal causa de vulneraciones del derecho al honor o a la intimidad cuando no se cumple.

La STC 105/1990 aclara el concepto de veracidad, al señalar que «lo que el requisito constitucional de veracidad viene a suponer es que el informador tiene-si quiere 
Manuel Carrasco Durán - Criterios Jurisdiccionales para la resolución...

situarse bajo la protección del artículo 20.1.d)- un especial deber de comprobar la veracidad de los hechos que expone, mediante las oportunas averiguaciones, y empleando la diligencia exigible a un profesional. Puede que, a pesar de ello, la información resulte errónea, lo que obviamente no pude excluirse totalmente. Pero las afirmaciones erróneas son inevitables en un debate libre, de tal forma que de imponerse "la verdad" como condición para el reconocimiento del derecho, la única garantía de la seguridad jurídica sería el silencio. Información veraz en el sentido del artículo 20.1.d) significa, pues, información comprobada según los cánones de la profesionalidad informativa, excluyendo invenciones, rumores o meras insidias."

Por lo tanto, veracidad no es sinónimo de verdad. No se puede exigir al periodista que los hechos sobre los que informe sean ciertos. Tampoco se puede imponer una única versión de los acontecimientos, ya que un mismo hecho puede ser explicado de diversas maneras, todas ellas verídicas desde un punto de vista plural ${ }^{10}$. Lo que se exige es que el periodista haya sido diligente en la averiguación de la información, esto es, que haya investigado los hechos y comprobado la fiabilidad de sus fuentes de información con la diligencia adecuada, según los usos de su profesión, la trascendencia de la información que se publica y el celo medio exigible a quien tiene la responsabilidad de divulgar datos que pueden afectar al honor o la intimidad de las personas, descartando la negligencia, el descuido o la precipitación en la comunicación de este tipo de informaciones.

Ello supone que el informador haya hecho lo posible para dar la información de la manera más correcta y que haya tenido una actitud positiva hacia la verdad (no se ampara a quien "defraudando el derecho de todos a la información, actúe con menosprecio de la veracidad o falsedad de lo comunicado", según la STC 6/1988), en suma, que el hecho haya sido comprobado de manera razonable con otros datos objetivos o que el informador haya contrastado su veracidad realizando las verificaciones oportunas. "Tal obligación, sin embargo, debe ser proporcionada a la trascendencia de la información que se comunica, dependiendo, necesariamente, de las circunstancias que concurran en cada supuesto en concreto (STC 219/1992). La contrastación de la noticia no es, pues, un término unívoco, sino que, más allá de su genérica formulación como deber, exige matizaciones casuísticas. Así, cuando la noticia que se divulga puede suponer por su propio contenido un descrédito en la consideración de la persona a la que la información se refiere, esa obligación de comprobar la veracidad del contenido de la información adquiere, en principio, su máxima intensidad, aunque pueden existir circunstancias que modulen dicha obligación, como, entre otras, el carácter del hecho noticioso, la fuente que proporciona la noticia, las posibilidades efectivas de contrastarla, etc.» (STC 240/1992).

Además de la veracidad de la información, dos requisitos más deben exigirse a aquélla. Primero, que la información ha de versar sobre hechos objetivos y reales. No se trata de transmitir fríamente la narración mecánica de un acontecimiento, ya que los hechos se pueden valorar, pero no manipular para desvirtuarlos. Segundo, que los hechos han de ser comprobados razonablemente, o, como dice la STC 6/1988, que "hayan sido objeto de previo contraste con datos objetivos", de modo que no es veraz

${ }^{10}$ DE CARRERAS SERRA, L.; Régimen jurídico de..., p. 47 
la noticia que se da como verídica, pero que sólo se sustenta en rumores, invenciones o insinuaciones insidiosas.

La veracidad, por lo tanto, no se refiere a los hechos sobre los que se informa, sino a la actitud del periodista en la comprobación de la realidad de aquellos sobre lo que informa y de la fiabilidad de sus fuentes de información. Si, pese a su actitud diligente, se comprueba posteriormente que la información es errónea, tal información no queda desprotegida si cumple con los requisitos citados, y, por lo tanto, prevalecerá aunque haya resultado afectado el derecho al honor o la intimidad de alguien. Cumpliendo tales requisitos, pues, la libertad de expresión incluye las informaciones erróneas o no probadas en juicio (STC 6/1988). Es lo que ocurrió en el caso resuelto por la STC 240/1992, acerca de una noticia en la que se decía, entre otras cosas, que el párroco de un pueblo había comandado, a golpe de garrote, el asalto de un grupo de vecinos contra unos bañistas que descansaban en una playa nudista. Se demostró que el periodista había confundido el nombre del pueblo del cual provenía el párroco y que se trataba, en realidad, de otro párroco, pero la actitud del periodista, el contraste de sus fuentes de información, el tratamiento de la noticia, el hecho de que no se hiciera énfasis en las circunstancias personales del asunto, sino que se tratara más bien de exponer el contraste de unos comportamientos modernos dentro de un pequeño pueblo de costumbres tradicionales, y otras circunstancias, entre las que hay que destacar que, advertido el error, fue rectificado en el mismo periódico, hicieron que el Tribunal Constitucional considerara que el supuesto quedaba amparado por la libertad de información.

Del mismo modo, la STC 171/1991 (accidente de avión-1) advierte que el error informativo causado por la determinación inexacta de la causa por la que en una ocasión anterior había sido despedido el piloto objeto de la noticia no suponía lesión en el derecho al honor, ya que el periódico había publicado posteriormente una rectificación, lo que demostraba que el error no había sido malicioso. Como señala la sentencia, «los errores informativos intrascendentes han de estimarse protegidos también por el derecho constitucional de información. De otro modo, la posibilidad ilimitada de acciones civiles por tales pequeños errores podría ser una amenaza latente que pusiese en peligro el espacio constitucionalmente protegible en una sociedad democrática para la comunicación libre de informaciones."

No sólo a los periodistas se aplica el requisito de la veracidad. También debe respetarlo cualquiera que realice afirmaciones para su difusión pública en relación con personas determinadas. Así, constituye vulneración del derecho al honor haber dado un representante sindical una rueda de prensa comunicando que el Delegado de trabajo de la provincia tenía por costumbre solucionar los conflictos en las empresas mediante comidas con los empresarios y sobornos, sin aportar ninguna prueba sólida de sus afirmaciones. Es éste un caso prototípico de difusión negligente de rumores o insinuaciones insidiosas.

Cuando la información recoge declaraciones o afirmaciones de terceros (por ejemplo, las entrevistas), el medio de comunicación responde del hecho de las declaraciones y el entrevistado del contenido de sus afirmaciones, aunque, en todo caso, para que la publicación de la declaración se pueda amparar en el derecho de información, debe versar, como veremos seguidamente, sobre hechos de "relevancia pública" (STC 232/1993). Cuando se trata de cartas al director, una sentencia posterior del Tribunal Constitucional entendió que el contenido de la carta sólo es atribuible al medio de co- 
municación si la publica desconociendo u ocultando el nombre del autor de ella. Si publica el nombre de su autor, la posible responsabilidad por su contenido se atribuye a él.

La veracidad no es el único requisito para entender que el ejercicio de la libertad de información haya sido correcto. Además, se requiere que la información verse sobre “hechos noticiables» (STC 107/1988). Con más precisión, señala la STC 171/1990 (accidente de avión-1) que es necesario «que la información tenga relevancia pública, lo cual conlleva que la información veraz que carece de ella no merece la especial protección jurisdiccional», esto es, que «las intromisiones en el honor e intimidad personal requieren ... también que su contenido se desenvuelva en el marco del interés general del asunto al que se refiere; de otra forma el derecho de información se convertiría en una cobertura formal para, excediendo el discurso público en el que debe desenvolverse, atentar, sin límite alguno y con abuso de derecho, al honor y la intimidad de las personas, con afirmaciones, expresiones y valoraciones que resulten injustificadas por carecer de valor alguno para la formación de la opinión pública sobre el asunto de interés general que es objeto la información».

Se exige, por lo tanto, que la información verse sobre hechos en los que quepa identificar un valor informativo para el interés público y que los hechos expuestos estén relacionados con el motivo informativo principal, de modo que no puede aprovecharse una información para publicar hechos ajenos a la realidad sobre la que se pretende informar y que no tengan valor informativo alguno. Por ejemplo, en un caso acerca de un crimen pasional, puede informarse acerca de todas las circunstancias relativas a dicho suceso y a las personas que pudieron haber intervenido en él, pero no admitió el Tribunal Constitucional la insinuación de que la principal sospechosa ejercía la prostitución porque era amiga de doña $\mathrm{X}$, de la cual, se decía en la información, era fama en el pueblo que se dedicaba a dicha actividad, y que ambas amigas se juntaban en un determinado bar. Quién sea amiga la acusada y a qué se dedique es, claramente, algo extraño al propósito de informar sobre aquel crimen. Además, quedó claro en el juicio que el periodista se había basado para hacer tales afirmaciones en un simple rumor, cogido al vuelo, expresado por alguna persona habitante del pueblo donde se produjo el suceso.

Es interesante comprobar las distintas soluciones que nuevamente adopta el Tribunal Constitucional en sus SSTC 171/1990 y 172/1990 (accidente de avión) con respecto a este punto. En la primera de ellas, parte del dato de que «resulta innegable la relevancia pública y social del accidente y de sus posibles causas, incluso de si el mismo podía deberse a un eventual fallo humano del piloto. La competencia, aptitud y actuación profesional de un piloto en un servicio público de transporte aéreo han de considerarse temas de interés social y de relevancia para el público que traspasan los límites de la esfera privada. Las condiciones en que se encontraba y la conducta profesional de quien, como piloto, realiza un servicio público y en aquello que a éste atañe ha de considerarse sometida a crítica y escrutinio públicos también por parte de los medios de comunicación, por ser temas de relevancia pública.» En consecuencia, entiende conforme con la Constitución una noticia que informa de que, con ocasión de una huelga y por su carácter conflictivo, el piloto había sido despedido una vez con motivo de una agresión a un comandante que no se adhirió a la huelga, otra en la que se difunde que la vida privada del piloto iba a ser investigada para determinar si podía influir en la seguridad de los vuelos en que intervenía, otra en la que se menciona un expediente 
relacionado con el piloto y se viene a atribuir el cese del Director de la Compañía "lberia», entre otras causas, a esos informes sobre el mencionado piloto, con un entrecomillado, y otra más en la que se insiste en la información anterior entrecomillando "algo más que un curso de refresco para volver a volar" y mencionando expresamente la «forma irreflexiva de volar del comandante Patiño».

Por el contrario, en la STC 172/1990 (accidente de avión-2), además de considerar fuera de lugar las opiniones vejatorias ya señaladas sobre el piloto del avión siniestrado ("cachondo mental» y "mal educado y grosero"), también entiende el Tribunal ajena a la información que se pretende comunicar la afirmación de que el piloto, casado y con hijos, vivía con otra mujer, una azafata de Iberia, que se encontraba embarazada de siete meses, ya que, como dice la sentencia, «tal afirmación, que de ser cierta podría quizá, en determinadas circunstancias, venir amparada en el derecho de información si se refiriese a un personaje público (véase lo que decimos en un apartado posterior de este artículo), no puede en modo alguno encontrar justificación en el caso aquí debatido, pues se trata de una persona privada, cuya participación en un hecho de interés general ocurrido en el ejercicio de su profesión puede autorizar al informador a someter a crítica su personalidad como gestor del servicio público de transporte aéreo, pero no a entregar a la curiosidad de la opinión pública aspectos reservados de su vida privada más íntima, que en absoluto tienen la más mínima conexión con el hecho de la información." De igual modo, carece de valor informativo la publicación de que un arquitecto tenía SIDA y el nombre del compañero con quien vivía (STC 20/1992).

Los asuntos pueden ser de interés general «por las materias a que se refieren y por las personas que en ellos intervienen" (STC 107/1988). El último supuesto será tratado más detenidamente en el siguiente apartado del presente trabajo.

Para terminar con este apartado, señalaremos que se admite la práctica frecuente de incluir en la información «elementos valorativos, que no llegan a desnaturalizar el derecho a la información, siempre que el elemento preponderante de lo comunicado sea el informativo, debiéndose a este respecto señalar que la valoración de los hechos constituye también un elemento fundamental del derecho de información, en el cual se incluye la actitud crítica, incluso enérgica o áspera, siempre que los términos en que se exteriorice no sean desmesurados o desproporcionados con la finalidad de oposición o repulsa que la misma pretende, no siendo, por ello, exigible que las informaciones difundidas por los medios de comunicación social, que no se limiten al simple comunicado de noticias, sean neutrales o estrictamente objetivas, ya que lo contrario equivaldría a limitar el principio de pluralismo más allá de lo que consiente su condición de valor esencial de la sociedad democrática, dejando reducida la libertad de información a inocua transmisión mecánica de hechos noticiables" (STC 172/1990, accidente de avión-2).

Considera la STC 171/1990 (accidente de avión-1) que el hecho de encontrarse sub iudice los hechos objeto de la información y estar siendo objeto de investigación judicial no suponía vulneración del derecho al honor, ya que, como subraya el Tribunal Europeo de Derechos Humanos, «incluso si se hubiera podido conducir a ciertas personas a formarse una opinión sobre el problema de la negligencia, ésta no hubiera tenido consecuencias adversas para la "autoridad del Poder Judicial"» (Tribunal Europeo de Derechos Humanos, caso The Sunday Times, sentencia de 26 de abril de 1979, núm. 63 ). Sólo se produciría, pues, un supuesto de «juicio paralelo» en un medio de comuni- 
cación, en relación con hechos objeto de investigación judicial simultánea, cuando «de las circunstancias del caso (pudiera) deducirse que la información publicada haya puesto en peligro la imparcialidad y el prestigio de los Tribunales" (STC 171/1990), o si se dan límites fijados en la ley a los derechos de información para garantizar la autoridad y la imparcialidad del Poder Judicial, cuando lo exija una necesidad social imperiosa, posibilidad esta última que ha sido interpretada muy restrictivamente por la jurisprudencia del Tribunal Europeo de Derechos Humanos.

\subsubsection{La consideración de la condición pública o privada de las personas}

El límite que el honor, la intimidad y el derecho a la propia imagen de las personas suponen a las libertades de expresión y de información pierde parte de su eficacia cuando lo publicado se refiere a personas de relevancia pública, bien por ocupar puestos de en órganos de carácter político o administrativo, bien porque su profesión o su comportamiento las dote de especial notoriedad entre el público. Estas personas son una fuente de hechos noticiables, aptos, por lo tanto, para ser objeto de informaciones y opiniones, cuando éstas se refieren, en el primer caso, a circunstancias derivadas del desempeño de sus funciones públicas, o bien, en el segundo supuesto, cuando se refieren a datos relativos a su situación, a sus acciones y a sus relaciones en la sociedad. Ello hace que los límites indicados, como se ha dicho, cedan, en tales ocasiones, ante el valor noticioso de los datos u opiniones que se comunican al público.

La STC 105/1990 señala que las personalidades públicas, «al haber optado libremente por tal condición, deben soportar un cierto riesgo de una cesión de sus derechos de la personalidad, por lo que, en correspondencia, se debilitaría la eficacia de tal protección en los supuestos de información y opinión sobre conductas privadas de carentes de interés público."

Ello tiene dos importantes consecuencias. La primera es que las personas públicas han de soportar los juicios desaprobatorios de los demás cuando se refieren a hechos ocurridos en el ejercicio de su labor pública, ya se trate de funcionarios o cargos públicos, ya de personas que realicen un trabajo cuyas consecuencias tengan una clara repercusión pública, como el caso, ya examinado, del piloto de avión. Ahora bien, en estos casos de personas públicas por un determinado trabajo, cargo o función, sólo se admiten informaciones relativas al desempeño de aquel trabajo, cargo o función. Recuérdese que la STC 172/1990 (accidente de avión-2) considera ajena a la información que se pretende comunicar la afirmación de que el piloto, casado y con hijos, vivía con otra mujer, una azafata de lberia, que se encontraba embarazada de siete meses, ya que «tal afirmación, que de ser cierta podría quizá, en determinadas circunstancias, venir amparada en el derecho de información si se refiriese a un personaje público, no puede en modo alguno encontrar justificación en el caso aqui debatido pues se trata de una persona privada, cuya participación en un hecho de interés general ocurrido en el ejercicio de su profesión puede autorizar al informador a someter a crítica su personalidad como gestor del servicio público de transporte aéreo, pero no a entregar a la curiosidad de la opinión pública aspectos reservados de su vida privada más íntima, que en absoluto tienen la más mínima conexión con el hecho de la información." La segunda consecuencia es que las personas que por su propio comportamiento en público se hacen a sí mismas objeto de la curiosidad y del examen social han de soportar informaciones y juicios de valor sobre hechos y comportamientos que, en relación con el común de las personas, quedan dentro de la esfera de su intimidad, pero que, cuando se trata de 
este tipo de personas de relevancia pública, concitan un interés público que los convierte en dato noticiable.

No sólo las personas que se dedican a actividades públicas o tienen un cierto poder público son de relevancia pública, sino que han de considerarse también personas públicas aquéllas que, no teniendo contacto con la política, se dedican a «actividades que persiguen notoriedad pública" (STC 172/1990). En particular, los artistas profesionales del espectáculo (o quienes pretenden llegar a serlo), encuentran un tope a su derecho a su imagen en «las limitaciones derivadas de la publicidad de sus actuaciones o su propia notoriedad", cuando "consienten con frecuencia la captación o reproducción de su imagen, incluso con afección a su intimidad, para que pueda ser objeto de explotación comercial» (STC 117/1994). Es, por así decir, el precio de la fama o de la exhibición frívola o narcisista de la intimidad o la imagen ${ }^{11}$, que, al exponerla ordinariamente a la observación pública, relaja también los términos de su protección.

Se distinguen, pues, dos grupos de personas públicas: aquéllas que lo son por la relevancia y las consecuencias públicas del cargo, función o profesión que desempeñan, respecto de las que se admite la crítica sólo en relación con las circunstancias que afecten al desarrollo de su labor, y aquéllas que lo son por sus actuaciones en la vida social, que abren al conocimiento público esferas de su vida pertenecientes al ámbito de su intimidad, y deben soportar, por lo tanto, las informaciones y opiniones sobre el ámbito de comportamientos y circunstancias que entregan al conocimiento público y que, por ello, pierden ya el carácter íntimo que tendrían de no mediar esta exposición al público.

Ahora bien, lo anterior no quiere decir que este último tipo de personas de relevancia pública dejen de tener derecho al honor o a su intimidad. Las exigencias de estos derechos se hacen más elásticas en estos casos, pero, aun así, la libertad de información y la libertad de expresión no cubren la divulgación de hechos u opiniones sin interés para la formación de la opinión pública cuando se deduzca claramente del comportamiento de la persona famosa que quiso dejar tales realidades preservadas del conocimiento público, cuando pueda deducirse dicha intención de la fuerte carga íntima de los hechos publicados o cuando los hechos objeto de la información hayan tenido lugar en lugares que no sean abiertos al público.

Esto último es lo que ocurrió en el famoso caso resuelto por la STC 231/1988. En ésta, el Tribunal Constitucional amparó a la cantante Isabel Pantoja en la lesión de su derecho a la intimidad que había sufrido a causa de la divulgación por televisión de un vídeo rodado en la enfermería de la plaza de toros de Pozoblanco, en el cual, por decirlo gráficamente, se había filmado en directo la muerte de su marido, el torero Paquirri, que acababa de sufrir la cogida de un toro. En el vídeo se observaban claramente las heridas sufridas por el torero, su estado anímico, su dolor, las imágenes de sus gestos y de su rostro y su evolución hasta poco antes del momento de su muerte. Consideró la sentencia que ni «la enfermería, por la propia naturaleza de su función, puede asi considerarse como un lugar abierto al público ( $y$ de hecho, los que allí entraron fueron conminados a desalojar el lugar), ni la reacción del señor Rivera ante sus heridas, el ejercicio de una profesión de notoriedad pública."

11 RUIZ-GIMÉNEZ, J.; Dialèctica de la llibertat de comunicació i el respecte a la intimitat, Centre d'Investigació de la Comunicació, Generalitat de Catalunya, Barcelona, 1991, p. 29, citado por CARRERAS SERRA, L.; Régimen jurídico de..., p. 95. 
El caso anterior pone de manifiesto las diferencias en el concepto acerca de lo que sea propio de la profesión periodística que pueden mantener en ocasiones el mundo del periodismo y el del derecho. Mientras el Tribunal Constitucional consideró el vídeo como un supuesto de intromisión en el derecho a la intimidad, dicho vídeo fue premiado en un festival periodistico internacional.

El Tribunal Supremo, por su parte, consideró en sentencia de 29 de marzo de 1988 que atentaba contra la intimidad de una conocida actriz la publicación de una fotografía suya, tomada con teleobjetivo, en top-less en una playa (por lo tanto, lugar abierto al público), pero poco concurrida. La sentencia toma en consideración que el lugar apartado donde se captó la imagen presupone el propósito de la actriz de preservar su intimidad y entiende que esta actitud pone de relieve su falta de consentimiento. No obstante, como señala Lluís de Carreras, "es dudoso que esta doctrina se generalice, y probablemente la solución se deberá encontrar caso por caso. El concepto de lugar retirado o no retirado es muy indeterminado. Lo mismo ocurre con el concepto de intimidad en un lugar abierto al público." Además, el Tribunal Supremo se confunde cuando habla de intimidad, que es un concepto diferente al de la propia imagen ${ }^{12}$.

Finalmente, citaremos un caso resuelto por sentencia del Tribunal Supremo de 17 de julio de 1993. En esta ocasión, una famosa señora, asidua de las páginas de las revistas de sociedad, había sido sorprendida bailando en una discoteca sin ropa interior debajo de la falda. El fotógrafo que advirtió la circunstancia halló el modo de colocarse en posición de retratar las partes más íntimas de su anatomía ${ }^{13}$. La sentencia basó su condena en la falta de consentimiento de la perjudicada, en que, pese a su condición de persona de fama, la divulgación de sus circunstancias personales había quedado "siempre limitada al ámbito doméstico y social propio de su posición», en "la carencia de interés social legítimo de las imágenes publicadas por el contenido de las mismas", en la negación de que la divulgación de las imágenes obtenidas obedeciera a satisfacer la exigencia de información, acentuando el aspecto íntimo de las mismas, particularmente preservado del conocimiento de los demás y no amparado por el fin legitimador de un interés informativo, $y$, finalmente, en que la publicación de aquellas fotografías atacaba «la libertad en la esfera personalísima, en principio más celosamente guardada $y$, por consiguiente, más estrictamente sustraída al desvelamiento y conocimiento ajeno de lo íntimo corporal, inserto en la intimidad personalm.

Hasta aquí, el pronunciamiento del Tribunal puede parecer evidente. Sin embargo, hay que subrayar una circunstancia: la publicación de aquellas fotografías supuso un tremendo éxito para la revista Interviú, al punto de que pocas horas después de ponerse a la venta, se agotó en toda España la tirada de la revista. De aquí se deduce

12

2 Asi, el auto del Tribunal Constitucional 300/1989 considera que la publicación de la fotografía de una señora sin su consentimiento constituiría "una intromisión ilegítima en el derecho fundamental a su propia imagen". Ahora bien, debe subrayarse que, de acuerdo con el artículo $8^{\circ}$ de la $\mathrm{LODH}$, el derecho a la propia imagen no impide

a) Su captación, reproducción o publicación por cualquier medio, cuando se trate de personas que ejerzan un cargo público o una profesión de notoriedad o proyección pública y la imagen se capte durante un acto público o en lugares abiertos al público.

b) La utilización de la caricatura de dichas personas, de acuerdo con el uso social.

c) La información gráfica sobre un suceso o acaecimiento público cuando la imagen de una persona determinada aparezca como meramente accesoria.

Las excepciones de las letras a) y b) no son de aplicación con respecto a las autoridades o personas que desempeñen funciones 13 que por su naturaleza necesiten el anonimato de la persona que las ejerza

Como dice la propia sentencia, la "zona de pubis y genital externa" 
una consecuencia muy importante: cuando se habla de valor informativo, el Tribunal debe hacer un esfuerzo por considerar dicho valor desde posiciones abstractas $u$ objetivas, en atención a la cualidad sustancial del objeto de la información, más allá de las preferencias reales que pueda manifestar un público, llevado de su curiosidad o del morbo, por informaciones de escasa sustancia informativa. Así, como dice la STC 20/1992, "la preservación de ese reducto de inmunidad sólo puede ceder, cuando del derecho a la información se trata, si lo difundido afecta, por su objeto y por su valor, al ámbito de lo público, no coincidente, claro es, con aquello que pueda suscitar o despertar, meramente, la curiosidad ajena,"

Cuestión distinta es lo que ocurre con comportamientos en lugares públicos de personas famosas, que, incluso, hacen de su aparición en algunos medios de prensa uno de los instrumentos para mantener la popularidad necesaria al objeto de incrementar la cotización de su imagen o de su presencia en acontecimientos sociales. En tales casos, pese al escaso valor informativo, en sentido objetivo, de las noticias relativas a dichos personajes, su abierta actitud general en sociedad hace que se entienda que han renunciado a mantener sobre tales comportamientos la reserva connatural a su intimidad, por lo que dichos comportamientos quedan expuestos a la observación pública. Quien hace de la aparición en los medios de comunicación uno de los instrumentos normales para mantener su prestigio profesional o social no puede quejarse si le disgusta el tratamiento que alguno de aquellos medios da a sus apariciones públicas o a circunstancias de su vida personal, cuando la trayectoria de esa persona demuestra que no ha sido mínimamente celosa a la hora de preservar la reserva sobre esa propia vida personal. No puede demandar protección quien consiente expresa o tácitamente la intromisión en su intimidad, ya en la generalidad de los casos, ya en un supuesto específico, como ocurre en el caso resuelto por el auto del Tribunal Constitucional 300/1989, en el que "la forma poco natural» en que aparecía la imagen de la señora en la fotografía publicada "evidencia una clara actitud para ser fotografiada».

En todo caso, es importante señalar que es la actitud individual de cada cual la que delimitará qué espacios de su vida íntima quedan expuestos a la divulgación y enjuiciamiento públicos y cuáles, sin embargo, permanecen reservados. Será distinta la solución en el caso de personas famosas por su actividad artística que guarden un comportamiento discreto en su vida social que cuando se trate de otras que acostumbren servirse de la curiosidad pública como medio para promocionar su imagen o su popularidad haciendo noticiables, por su propia actitud y su comportamiento, parcelas de su vida que, de no mediar estas actitudes, podrían ser calificadas como íntimas.

Por el contrario, «la eficacia justificadora de dichas libertades (de expresión y de información) pierde su razón de ser en el supuesto de que se ejerciten en relación con conductas privadas carentes de interés público y cuya difusión y enjuiciamientos públicos son innecesarios, por tanto, para la formación de la opinión publica libre en atención a la cual se les reconoce su posición prevalente" (STC 107/1988).

\subsubsection{La protección de la juventud y de la infancia}

Mencionamos anteriormente que la Constitución recoge también la protección de la juventud y de la infancia como límite a las libertades de expresión y de información. Destacaremos tres pronunciamientos del Tribunal Constitucional en relación con este aspecto. Una STC de 23 de febrero de 1995 consideró que la Administración de Correos está capacitada para tomar decisiones restrictivas de dichas libertades, como 
en el caso era la negativa a distribuir determinadas revistas pornográficas por correo, como medida para la protección de la juventud y de la infancia. No obstante, entendió también el Tribunal Constitucional que la posibilidad de tomar una medida de este cariz, como limitadora de un derecho fundamental, debía estar contemplada en una norma con rango de ley. Como conclusión, el Tribunal concedió el amparo al editor de las revistas, ya que la Administración se había basado para su decisión en un Real Decreto, es decir, una norma de carácter reglamentario que no podía restringir los derechos fundamentales.

Naturalmente, la protección de la juventud y la infancia no puede dar lugar a un régimen de censura previa de las publicaciones, lo cual resulta excluido expresamente por el artículo 20.2 de la Constitución. Así, "la pornografía no constituye para el ordenamiento jurídico vigente, siempre y en todos los casos un ataque contra la moral pública en cuanto minimum ético acogido por el derecho, sino que la vulneración de ese minimum exige valorar las circunstancias concurrentes $y$, entre ellas, muy especialmente tratándose de publicaciones, la forma de publicidad y de la distribución, los destinatarios -menores o no- e incluso si las fotografías calificadas contrarias a la moral son o no de menores, y el texto en la parte que se califique así trata de actuaciones o no de menores, pues no cabe duda (de) que cuando los destinatarios son menores -aunque no lo sean exclusivamente- $y$ cuando éstos son sujeto pasivo y objeto de las fotografías y el texto, el ataque a la moral pública, y por supuesto a la debida protección a la juventud y a la infancia, cobra una intensidad superior" (STC 62/1982). En el caso concreto, el Tribunal Constitucional desestimó el recurso de amparo formulado por el recurrente contra la sentencia en la que se le condenaba por un delito de escándalo público, de acuerdo con la normativa entonces vigente, como editor y distribuidor de un libro en cuya portada se indicaba que era "para niños y para padres" y que, con el pretexto de la educación sexual, contenía multitud de imágenes y términos altamente inapropiados para los menores a los cuales se dirigía. Es, como se ve, una solución a posteriori para sancionar el caso concreto de acuerdo con las circunstancias específicas concurrentes en él y con su carácter transgresor de un límite a la libertad de información que aparece en la propia Constitución, por lo que la medida represiva es, en este caso concreto, perfectamente lícita conforme a la Constitución. Lo que ésta no permite, sin embargo, son medidas abstractas que impidan de forma genérica la difusión de este tipo de publicaciones, ya que la única solución posible es examinar caso por caso si puede considerarse que las características y forma específicas de alguna de ellas transgreda algún límite que la Constitución permita oponer al principio general favorable a la libre difusión de publicaciones.

Finalmente, la STC 197/1991 trata el caso del hijo adoptado por una famosa actriz y cantante y su marido. Éstos quisieron dar a conocer el hecho a la prensa sin identificar a la madre natural del niño, pero un medio de comunicación localizó poco después a la madre y divulgó su identidad y sus circunstancias personales. El medio de comunicación alegó que, al haber hecho públicos determinados datos concernientes a su vida familiar, los recurrentes habían excluido este ámbito de su esfera íntima, y debian soportar las investigaciones periodísticas conducentes a la contrastar la veracidad de los hechos, rectificar errores o denunciar falsedades. El Tribunal consideró que esta afirmación habría sido válida si no hubiese una tercera persona, el menor, incluida en la relación, y cuyos intereses había que proteger específicamente, por lo que, finalmente, entendió que prevalece el derecho a la intimidad del menor con respecto a los datos no 
desvelados en la rueda de prensa, $\mathrm{y}$, como reflejo, también el derecho a la intimidad familiar. Asimismo, el Tribunal Constitucional utilizó el precepto sobre protección de la infancia y la juventud como apoyo adicional a su tesis.

\section{Epílogo}

Para la elaboración del presente trabajo se han escogido asuntos que resultan particularmente esclarecedores acerca de la manera en que se aplican y ponderan los distintos elementos que entran en juego cuando se produce un conflicto entre las libertades de expresión e información y el derecho al honor, a la intimidad y a la propia imagen. Ciertamente, abundan en la jurisprudencia española asuntos que le dan un tono muy característicamente «llamativo», por denominarlo de alguna manera. También el tipo de información o de opiniones que algunos sectores sociales demandan y, sobre todo, la forma, más o menos "agresiva» en que determinado sector de la prensa puede pretender dar satisfacción a tal demanda (adviértanse los casos particulares de la prensa sensacionalista británica y alemana ${ }^{14}$, y de las llamadas "revistas del corazón» españolas e italianas) constituyen elementos propios de cada sociedad, determinados por la forma diferente que cada sociedad tiene de acercarse a los hechos noticiables y, previamente, de identificar cuáles son estos hechos, en su pretensión de obtener información sobre la realidad.

No obstante, más allá de cuáles sean los detalles característicos de la manera como los medios de comunicación seleccionan los hechos noticiables y dan concreto tratamiento informativo y valorativo a la noticia, el hecho es que las actitudes de la prensa y las curiosidades del público que dan origen a la mayoría de los supuestos de colisión entre el derecho de la comunicación y el derecho al honor y sus complementos traspasan las fronteras y nos acercan más de lo que parece. El tono sensacionalista de cierta prensa chilena y el dato, bastante significativo a este respecto, de que el programa que parezca más visto de las emisiones de Televisión Española Internacional en Chile sea "Corazón, Corazón" demuestra lo que se acaba de señalar. Probablemente, cierta propensión a la curiosidad morbosa constituya uno de los rasgos comunes a la condición humana.

Aun con todo lo anterior, la descripción de las circunstancias más específicas de los casos que se han puesto como ejemplo no tiene otra función que la de iluminar la categoría partiendo de la anécdota. Quiere decirse que la finalidad principal del presente trabajo, más que la de ofrecer un muestrario de casos aislados, ha sido exponer de la

\footnotetext{
14 Mientras redacto estas líneas, leo en el periódico que un Tribunal alemán ha condenado a la revista Bunte a indemnizar a Carolina de Mónaco por haber publicado unas fotografias en las que la Princesa aparecía sin pelo, lo cual hizo correr rumores acerca de la posibilidad de que padeciera cáncer. Señala el Tribunal que la publicación de aquellas fotografías violó el derecho a la privacidad de la Princesa.

La misma revista ha sido condenada en otro juicio por divulgar en 1997 que la Princesa se había casado con Ernesto de Hannover, ya que, como dice el Tribunal, la publicación de rumores completamente absurdos sobre las vidas privadas no está cubierta por el derecho general de libertad de prensa.

La práctica periodística del diario sensacionalista alemán Bild sirvió de base a Heinrich Böll, escritor y premio Nobel, para escribir su novela El honor perdido de Katharina Blum, en la cual ironiza, precisamente, sobre el particularísimo estilo informativo de aquel diario.

Las inquietudes suscitadas por la prensa sensacionalista británica son suficientemente conocidas y, por lo tanto, no hace falta insistir en ellas.
} 
forma más coherente y completa posible los criterios generales utilizados por el Tribunal Constitucional español a la hora de resolver los conflictos suscitados por el problema objeto de examen, dentro, claro está, de la forma sintética de exposición a que obliga un trabajo de estas características. Los mismos criterios y la misma forma de ponderación de elementos jurídicos y circunstancias sirve para la resolución de casos de estructura y significado análogos a los que se citan a mero título de ejemplo, independientemente de la mayor, igual o menor discreción o «tipismo" de sus circunstancias concretas.

Por lo tanto, es poniendo el énfasis en los criterios generales y abstractos deducidos de la jurisprudencia que se ha examinado como debe leerse este trabajo para llegar al sentido que se le ha querido dar. Estos criterios son, insistimos, de aplicación general para el examen de todos los casos de conflicto entre el derecho de la comunicación y el derecho al honor, a la intimidad y a la propia imagen. Las circunstancias anecdóticas de los casos concretos que se han examinado no tienen más valor que el de ilustrar los criterios abstractos, que tienen validez general para la resolución de cuantos supuestos de conflicto entre ambos derechos puedan presentarse, por encima de las circunstancias específicas, más o menos extremas o llamativas, de algunos casos individuales, que hemos descrito sólo por considerar que ponerlos como ejemplo ilustraba más claramente o podía hacer más amena la exposición principal. 